\title{
Article \\ Electronically Tunable Full Wave Precision Rectifier Using DVCCTAs
}

\author{
Niranjan Raj ${ }^{1}$, Sagar ${ }^{1}$, Rajeev Kumar Ranjan ${ }^{1}$ (D), Bindu Priyadarshini ${ }^{2}$ and Nicu Bizon ${ }^{3,4,5, *(\mathbb{D})}$ \\ 1 Department of Electronics Engineering, Indian Institute of Technology (ISM), \\ Dhanbad 826004, Jharkhand, India; niranjan.17dr000367@ece.ism.ac.in (N.R.); \\ sagar.17dr000477@ece.ism.ac.in (S.); rajeev@iitism.ac.in (R.K.R.) \\ 2 Department of Electrical and Electronics Engineering, Guru Gobind Singh Educational Society's Technical \\ Campus (GGSESTC), Bokaro 827013, Jharkhand, India bindup2k4@gmail.com \\ 3 Faculty of Electronics, Communications and Computers, University of Pitesti, 1 Targu din Vale, \\ 110040 Pitesti, Romania \\ 4 ICSI Energy, National Research and Development Institute for Cryogenic and Isotopic Technologies, \\ 240050 Ramnicu Valcea, Romania \\ 5 Doctoral School, Polytechnic University of Bucharest, 313 Splaiul Independentei, 060042 Bucharest, Romania \\ * Correspondence: nicu.bizon@upit.ro
}

Citation: Raj, N.; S.; Ranjan, R.K.; Priyadarshini, B.; Bizon, N.

Electronically Tunable Full Wave Precision Rectifier Using DVCCTAs. Electronics 2021, 10, 1262. https:/ / doi.org/10.3390/electronics10111262

\section{Academic Editors:}

Padmanabhan Balasubramanian and Thaiyal Naayagi Ramasamy

Received: 13 April 2021

Accepted: 22 May 2021

Published: 25 May 2021

Publisher's Note: MDPI stays neutral with regard to jurisdictional claims in published maps and institutional affiliations.

Copyright: (c) 2021 by the authors. Licensee MDPI, Basel, Switzerland. This article is an open access article distributed under the terms and conditions of the Creative Commons Attribution (CC BY) license (https:// creativecommons.org/licenses/by/ $4.0 /)$.

\begin{abstract}
This work presents a Voltage mode scheme of a full-wave precision rectifier circuit using an analog building block differential Voltage current conveyor transconductance amplifier (DVCCTA) including five NMOS transistors. The proposed design is essentially suited for low Voltage and high-frequency input signals. The operation of the proposed rectifier design depends upon the region of operation of NMOS transistors. The output waveform of the presented rectifier design can be made electronically tunable by controlling the bias Voltage. The functional correctness and Verification of the presented design are performed using $0.25-\mu \mathrm{m}$ TSMC technology under the supply Voltage of $\pm 1.5 \mathrm{~V}$. The absence of a resistor leads to a minimal parasitic effect. To obtain further insight on the robustness of the circuit, a Monte Carlo simulation and corner analysis are also presented. The circuit is Verified experimentally by incorporating a breadboard model with the help of commercially available ICs CA3080 (operational transconductance amplifier) and AD844AN (current feedback operational amplifier) and offers remarkable compliance with both theoretical and simulation outcomes. The presented design has been laid out on Cadence Virtuoso, which consumes a chip area of $9044 \mu \mathrm{m}^{2}$.
\end{abstract}

Keywords: current mode circuit; full-wave rectifier; DVCCTA; high input impedance; low output impedance

\section{Introduction}

Rectifiers are Very common in analog signal conditioning and processing circuits and have potential applications in areas such as AC Voltmeter, ammeter, wattmeter, RF demodulator, averaging circuit, polarity, and peak detectors [1]. The rectifier using a diode is not capable of rectifying the low-level signal having an amplitude less than the threshold Voltage of silicon and germanium. A precision full-wave rectifier circuit implemented using an operational amplifier can also be implemented with a View to overcoming threshold Voltage issues. The op-amp-based design can rectify the low-level signal amplitude without facing the threshold problem. However, the limitation of the slew rate offered by an op-amp distorts the signal at the output of the rectifier. Therefore, the op-amp-based rectifier design is not suitable for solving the threshold Voltage issue due to the small signal transient [2]. The small-signal transient problem can be resolved by using the current mode approach since it provides a higher slew rate over Voltage-mode counterparts. The precision rectifier implemented using current-mode analog building 
block can be used to overcome the small-signal transient problem and can be operated at low Voltage, high frequencies, and also provides tunability features.

Several rectifier designs are reported in the literature based on Various active blocks using a Voltage/current mode [2-22] approach for the full-wave rectifier. A full-wave rectifier circuit using one second-generation current conveyor (CCII) and one current mirror as an active element with two grounded and two floating resistors are reported in [2], but the design does not provide low output impedance and does not have tunability features. The rectifier circuit in [3] employs two CCII with four diodes and a few grounded and floating resistors but does not provide low output impedance. In [4], the rectifier circuit is designed using three current-controlled conveyors (CCCII) with more resistors but does not provide low output impedance. The rectifier circuit presented in [5] consists of one operational transconductance amplifier (OTA) with four diodes, one grounded and floating resistor each, but does not provide low output impedance as well as high input impedance. In [6], two CCII and three NMOS transistors are used to design the rectifier circuit but do not provide high input impedance and low output impedance. A rectifier circuit is presented in [7] using one Dual-X current conveyor with three NMOS transistors to provide high input impedance, but does not provide low output impedance. The rectifier circuit is presented in [8] using one CCII and one OA with three resistors. A minimal precision configuration full-wave rectifier circuit using two different types of active block namely CCII and universal Voltage conveyor (UVC) along with two diodes and a few resistors is used in [9]. Recently, a new Versatile precision full-wave rectifier circuit was reported in [10] using a current or Voltage conveyor as an active element with two diodes but it requires an additional Voltage reference. In [11,12], two CCII and four diodes are used to design the rectifier circuit, but do not provide low output impedance. A rectifier design is presented in [13] using two second-generation current conveyors (CCII), one PMOS transistor, one Voltage follower (VF) along with two floating/grounded resistors but do not provide high input impedance. In [14], one negative type CCII, two diodes, and one floating/grounded each resistor are used, but it also fails to provide high input impedance as well as low output impedance. In [15], high input impedance and low output impedance are achieved by using one CCII but an additional 28 MOS transistors are used with one grounded resistor and does not provide tunability features. In [16], two differential Voltage current conveyors (DVCC) and in [17] two current feedback operational amplifiers (CFOA) are used to implement rectifier, having high input impedance and low output impedance but the output Voltage is not tunable. The tunability features of precision rectifier design are not available in [2-17]. In [18], Voltage mode electronically tunable full-wave rectifier circuit is presented using a multi-output current controlled conveyor (MO-CCCII) and capable of tunability but neither offers a high input impedance nor a low output impedance since the circuit is designed using BJT techniques and uses one zero-crossing detector. High input impedance and low output impedance can be achieved in $[8,9,15-17]$, as mentioned in Section 8, while other existing rectifier designs do not provide both features. The rectifier design presented in $[6,7,17]$ does not require any passive elements for their circuit implementation. Moreover, recent articles in the literature [19-24] address the design of the rectifier, but do not provide tunability features. In [25], the current mode precision rectifier design is presented using EXCCII, but the circuit does not provide tunability features. A current-mode full-wave rectifier circuit using DDCC along with three passive resistors is presented in [26]. The full-wave precision rectifiers presented in $[27,28]$ do not provide high input impedance and low output impedance. Moreover, it is worth mentioning that the rectifier circuit in [25-28] does not provide tunability features. In [29], two OTA and DVCC based rectifier circuits have been demonstrated using diode and few grounded resistors. A full wave rectifier design has been presented in [30] consisting of CCCII active block, however no experimental Verification of the circuit is provided. In [31], the presented rectifier design is complex consisting of several BJT based ICs. CMOS based precision rectifier design has been presented in [32] consisting of current comparator, current mirrors and diodes. In [33], the rectifier circuit consists of three OTAs as active elements with few 
grounded resistors. The rectifier design in [34] consists of an OTRA block with several passive floating resistors. A diode based rectifier design has been presented in [35] using CDTA block as an active element. A current mode precision rectifier has been presented in [36] using an improved Wilson current mirror. Most of the rectifier circuits in [29-36] are not capable of providing tunability features.

The work carried out in this paper proposes a new precision full-wave rectifier circuit using two DVCCTA active blocks and five NMOS transistors and demonstrates its performance. The objective of the proposed full-wave rectifier is to provide high input impedance as well as low output impedance by utilizing the features of an analog building block without using passive components. The high input impedance minimizes the loading effect and the low output impedance provides the maximum output load Voltage. These two parameters are important properties of a rectifier to be used with other analog circuits. The proposed design can be made electronically tunable by controlling the output Voltage through the bias Voltage. The tunability feature provides an external parameter to control the rectified output of the proposed model without altering the other parameters of the design. The simulation result Validates the theoretical model of the proposed full-wave rectifier circuit. The circuit is Verified experimentally by making a prototype on a breadboard using commercially available ICs CA3080 (operational transconductance amplifier) and AD844AN (current feedback operational amplifier) and shows good agreement with theoretical and simulation results.

The organization of the paper is as follows: Section 2 provides brief description about the DVCCTA block and its properties. Section 3 describes the proposed full wave rectifier circuit along with its mathematical model. Non-ideal analysis and the effect of parasitic are discussed in Sections 4 and 5 respectively. The Validation of the rectifier design by simulation and experimental results is presented in Sections 6 and 7, respectively. Comparison of the proposed model with the existing literature has been discussed in Section 8. Finally, Section 9 provides the conclusion of the research work.

\section{DVCCTA-Building Block and Its Properties}

DVCCTA is an active analog hybrid building block designed by cascading differential Voltage current conveyor (DVCC) with an operational transconductance amplifier (OTA) where DVCC is a differential amplifier with unity gain feedback and current mirror $[23,24]$. The symbol of DVCCTA is shown in Figure 1. The impedance at input terminal $Y_{1}$ and $Y_{2}$ are Very high, so that the current through these terminals is zero. Terminal $X$ provides the difference between the Voltages appearing at terminals $Y_{1}$ and $Y_{2}$. The same current flows through both $Z$ and $X$ terminals. Transconductance $\left(g_{m}\right)$ is responsible for converting the current at terminal $\mathrm{O}$ to an analogous Voltage at terminal $\mathrm{Z}$. The tuning of the transconductance can be achieved by external Voltage $V_{c}$. Equation (1) denotes the port relationship in matrix form for an ideal DVCCTA:

$$
\left[\begin{array}{c}
V_{X} \\
I_{Y 1} \\
I_{Y 2} \\
I_{Z} \\
I_{O}
\end{array}\right]=\left[\begin{array}{ccccc}
0 & 1 & -1 & 0 & 0 \\
0 & 0 & 0 & 0 & 0 \\
0 & 0 & 0 & 0 & 0 \\
1 & 0 & 0 & 0 & 0 \\
0 & 0 & 0 & g_{m} & 0
\end{array}\right]\left[\begin{array}{c}
I_{X} \\
V_{Y 1} \\
V_{Y 2} \\
V_{Z} \\
V_{O}
\end{array}\right]
$$

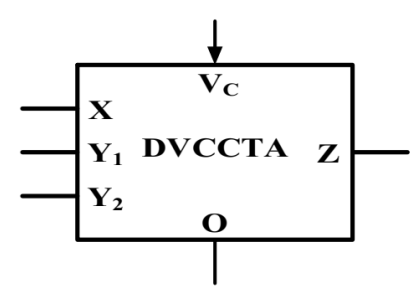

Figure 1. Symbol of DVCCTA. 
The CMOS-based internal structure of DVCCTA [23] is shown in Figure 2. The transconductance $\left(g_{m}\right)[23]$ is expressed in (2):

$$
g_{m}=k\left\{\left(V_{c}-V_{s s}\right) / 2-V_{t}\right\}
$$

where $k$ is $\mu \mathrm{CoxW} / \mathrm{L}, \mu$ is effective channel electron mobility, Cox represents the per unit area gate oxide capacitance, whereas $\mathrm{W} / \mathrm{L}$ denotes the aspect ratio of the MOS transistor.

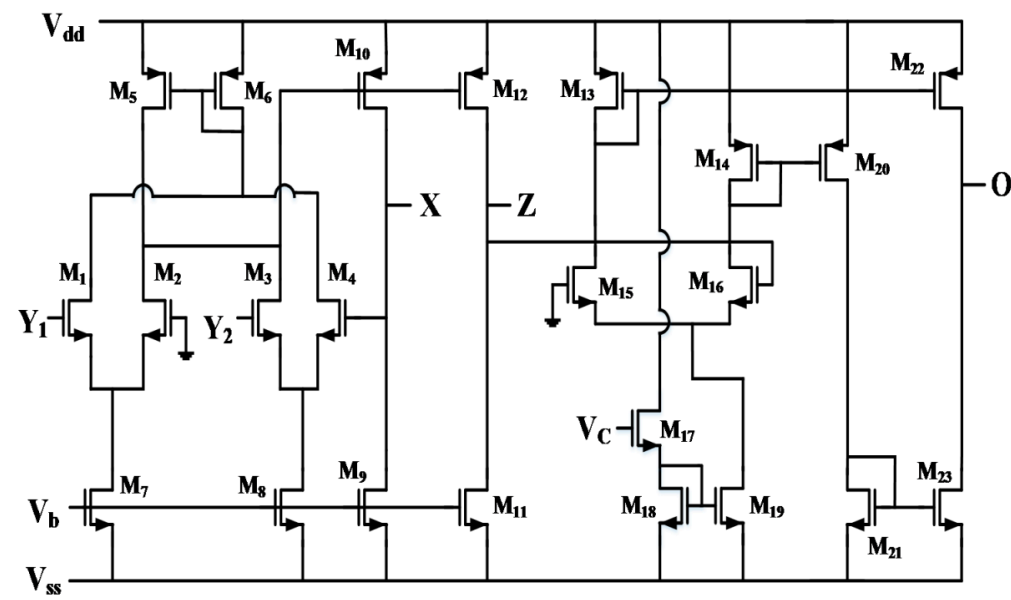

Figure 2. Internal structure of CMOS based DVCCTA.

Every MOS transistors used here are in the saturation region of operation. The rail-torail supply Voltage is shown as $\mathrm{V}_{\mathrm{DD}}$ and $\mathrm{V}_{\mathrm{SS}}$ respectively for positive and negative Voltage. $V_{t}$ represents the threshold Voltage of the MOS transistor. The transconductance $\left(g_{m}\right)$ can be controlled by adjusting the bias Voltage $V_{c}$. The aspect ratio for MOS transistors used in the DVCCTA design implemented here is shown in Table 1. The simulation is performed using $0.25 \mu \mathrm{m}$ TSMC process technology with the supply Voltage of $\pm 1.5 \mathrm{~V}$.

Table 1. Aspect ratio of MOS transistors used in DVCCTA.

\begin{tabular}{cc}
\hline Transistors & $W(\mu \mathrm{m}) / L(\mu \mathrm{m})$ \\
\hline $\mathrm{M}_{1}-\mathrm{M}_{4}$ & $10 / 0.5$ \\
\hline $\mathrm{M}_{5}, \mathrm{M}_{6}$ & $5 / 0.5$ \\
\hline $\mathrm{M}_{7}, \mathrm{M}_{8}$ & $27 / 0.5$ \\
\hline $\mathrm{M}_{9}, \mathrm{M}_{11}$ & $44 / 0.5$ \\
\hline $\mathrm{M}_{10}, \mathrm{M}_{12}$ & $8.5 / 0.5$ \\
\hline $\mathrm{M}_{13}-\mathrm{M}_{23}$ & $15 / 0.5$ \\
\hline
\end{tabular}

\section{Mathematical Model of the Proposed Full-Wave Rectifier Circuit}

In this section, a full-wave rectifier circuit using two DVCCTAs as active current mode building blocks along with five NMOS transistors is proposed as shown in Figure 3. The aspect ratio of NMOS transistors $\mathrm{M}_{\mathrm{A}}, \mathrm{M}_{\mathrm{B}}, \mathrm{M}_{\mathrm{C}}, \mathrm{M}_{\mathrm{D} 1}$, and $\mathrm{M}_{\mathrm{D} 2}$ are 30/0.5, 25/0.5, $23 / 0.5,5 / 0.5$, and $5 / 0.5$ respectively where $\mathrm{W}$ and $\mathrm{L}$ are in $\mu \mathrm{m}$. The implementation using transistor $\mathrm{M}_{\mathrm{D} 1}$ and $\mathrm{M}_{\mathrm{D} 2}$ represents an active resistor $\left(\mathrm{R}_{\mathrm{D}}\right)$ and its resistance can be controlled by using an external terminal $\left(V_{g}\right)$ as shown in Figure 3. The active resistor provides the required resistance without the cost of wasting large area on the chip. The effect of parasitic is least using active resistor compared to passive resistor and also provides relaxation in the matching requirements. Moreover, the resistance can be controlled using the external terminal of active resistor. A sinusoidal input signal Voltage is applied at terminal $Y_{1}$ of DVCCTA-1 for rectification. For the positive half-cycle of the applied input signal $\left(V_{i n}(t)+\right)$, transistor $M_{A}$ is in the cut-off region, transistors $M_{B}$, and $M_{C}$ is 
in the saturation region. The applied input Voltage is conveyed from the terminal $\mathrm{Y}_{1}$ of DVCCTA-2 to its $X$ terminal using the port relationships given in (1), giving rise to a current through the NMOS transistor $M_{B}$. Since the transistor $M_{A}$ is in the cut-off region, the current through terminal $X$ and $Z$ of DVCCTA-1 is zero. Using the port relationships of DVCCTA given in (1), the same current in the same direction passes through transistor $M_{B}$ and $\mathrm{M}_{\mathrm{C}}$. The current passing through transistor $\mathrm{M}_{\mathrm{B}}$ can be written as:

$$
I_{d 2}=\frac{K_{n}}{2}\left[V_{i n}(t)_{+}+V_{t n}-V_{t n}\right]^{2}=\frac{K_{n}}{2}\left[V_{i n}(t)_{+}\right]^{2}
$$

where $V_{t n}$ denotes the threshold Voltage and $K_{n}$ depicts the device parameter of the NMOS transistor. The expression for the current through the transistor $\mathrm{M}_{\mathrm{C}}$ can be written as:

$$
I_{d 3}=\frac{K_{n}}{2}\left[V_{Z}(t)+V_{t n}-V_{t n}\right]^{2}=\frac{K_{n}}{2}\left[V_{Z}(t)\right]^{2}
$$

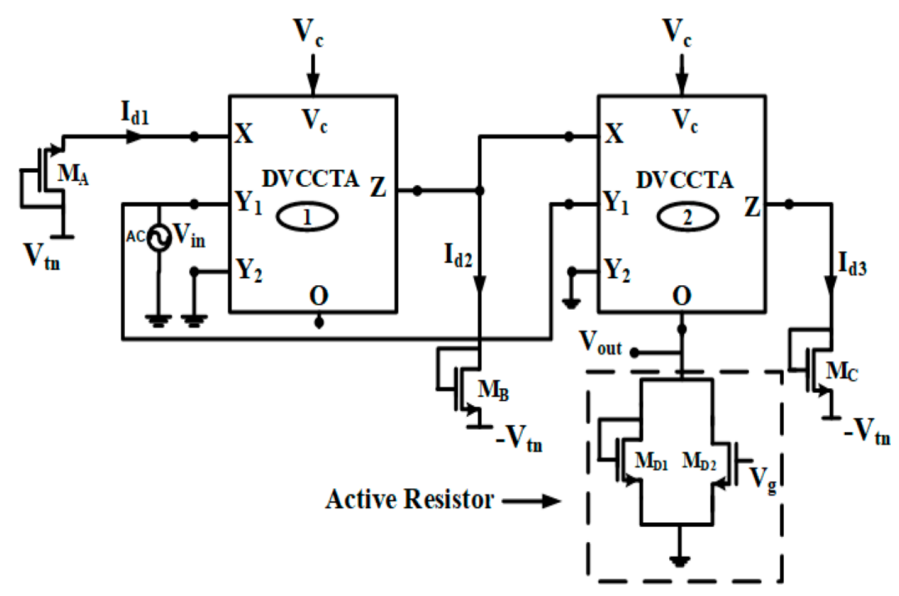

Figure 3. Full-wave rectifier circuit using DVCCTA.

Since the current through transistor $\mathrm{M}_{\mathrm{B}}$ and $\mathrm{M}_{\mathrm{C}}$ is same, the Voltage appearing at terminal Z of DVCCTA-2 is the same as the positive half-cycle of applied input Voltage and can be written as:

$$
V_{Z}(t)=V_{\text {in }}(t)_{+}
$$

For the negative half-cycle of the applied input Voltage $\left(V_{\text {in }}(t)_{-}\right)$, transistor $\mathrm{M}_{\mathrm{A}}$, $\mathrm{M}_{\mathrm{B}}$, and $\mathrm{M}_{\mathrm{C}}$ are in saturation, cut-off, and saturation region respectively. The applied input Voltage is conveyed from the terminal $\mathrm{Y}_{1}$ of DVCCTA- 1 to its $X$ terminal using the port relationships given in (1) and produces current passing through the NMOS transistor $\mathrm{M}_{\mathrm{A}}$. The same current in the same direction flows across the terminal $\mathrm{X}$ and $\mathrm{Z}$ of DVCCTA-1. Since the transistor $\mathrm{M}_{\mathrm{B}}$ is in the cut-off region, the current through terminal $\mathrm{X}$ of DVCCTA-2 is the same as the current through the Z terminal of DVCCTA-1. Using the port relationships given in (1), the current flowing through terminal Z and X of DVCCTA-2 is identical in the same direction. The current passing through transistor $\mathrm{M}_{\mathrm{A}}$ can be written as:

$$
I_{d 1}=\frac{K_{n}}{2}\left[V_{t n}-V_{i n}(t)_{-}-V_{t n}\right]^{2}=\frac{K_{n}}{2}\left[-V_{i n}(t)_{-}\right]^{2}
$$

The routine analysis yields the same current through transistor $M_{A}$ and $M_{C}$. The current passing through the transistor $\mathrm{M}_{\mathrm{C}}$ is given in (4). The Voltage appearing at terminal Z of DVCCTA-2 can be obtained by manipulating Equations (4) and (6). The Voltage at the $\mathrm{Z}$ terminal of DVCCTA-2 is found to be the same as the negative half-cycle of applied input Voltage and can be written as:

$$
V_{Z}(t)=-V_{i n}(t)_{-}
$$


Thus, the overall Voltage produced at terminal Z of DVCCTA-2 for a full-wave input signal can be written as:

$$
V_{Z}=\left|V_{\text {in }}(t)\right|
$$

The current produced at terminal O of the second DVCCTA can be written as:

$$
I_{o}=g_{m} V_{z}=g_{m}\left|V_{i n}(t)\right|
$$

The Voltage appearing at terminal $\mathrm{O}$ can be written as:

$$
V_{\text {out }}=g_{m} R_{D}\left|V_{\text {in }}(t)\right|
$$

where $R_{D}=\frac{1}{K_{n}\left(V_{g}-2 V_{t n}\right)}$, the resistance offered by NMOS transistor $\mathrm{M}_{\mathrm{D} 1}$ and $\mathrm{M}_{\mathrm{D} 2}$ connected at terminal O of DVCCTA-2. The input signal level must be taken into consideration while implementing the full-wave rectifier circuit using DVCCTA. The presented design of the full-wave rectifier circuit provides high input impedance and low output impedance. The proposed design is capable of providing tunability features and possesses the ability to rectify small-amplitude analog signals.

\section{Non-Ideal Analysis of the Proposed Rectifier Circuit}

Taking into account the non-ideal gain as a result of the physical implementation of DVCCTA, its port relationships as specified by (1) can be further modified as:

$$
V_{X}=\alpha_{i} V_{Y 1}-\alpha_{j} V_{Y 2} ; I_{Y 1}=I_{Y 2}=0 ; I_{Z}=\beta_{i} I_{X} ; I_{0}=\gamma_{i} g_{m} V_{Z}
$$

where $\alpha_{i}$ and $\alpha_{j}$ are the non-unity Voltage gain, $\beta_{i}$ is the non-unity current gain and $\gamma_{i}$ is the non-unity transconductance gain. Considering non-ideal current and Voltage gain, (3) can be rewritten as:

$$
I_{d 2}=\frac{K_{n}}{2}\left[\alpha_{2} V_{i n}(t)_{+}+V_{t n}-V_{t n}\right]^{2}=\frac{K_{n}}{2} \alpha_{2}^{2}\left[V_{i n}(t)_{+}\right]^{2}
$$

The potential at terminal Z of DVCCTA-2 for positive half-cycle using Equations (4), (11) and (12) can be expressed as:

$$
V_{Z}=\alpha_{2} \sqrt{\beta}_{2} V_{i n}(t)_{+}
$$

For the negative half-cycle of the applied input Voltage, (6) can be rewritten as:

$$
I_{d 1}=\frac{K_{n}}{2}\left[V_{t n}-\alpha_{1} V_{i n}(t)_{-}-V_{t n}\right]^{2}=\frac{K_{n}}{2} \alpha_{1}^{2}\left[-V_{i n}(t)_{-}\right]^{2}
$$

The Voltage at terminal Z of DVCCTA-2 for negative half-cycle using Equations (4), (11), and (14) can be written as:

$$
V_{Z}=-\alpha_{1} \sqrt{\beta_{1} \beta_{2}} V_{\text {in }}(t)_{-}
$$

Thus, the overall Voltage produced at terminal Z of DVCCTA-2 for a full-wave input signal can be written as:

$$
V_{Z}=\alpha_{2} \sqrt{\beta_{2}} V_{i n}(t)_{+}-\alpha_{1} \sqrt{\beta_{1} \beta_{2}} V_{\text {in }}(t)_{-}
$$

Considering the non-ideal gain, Equation (10) can be modified as:

$$
V_{\text {out }}=g_{m} R_{D} \gamma_{2}\left\{\alpha_{2} \sqrt{\beta_{2}} V_{\text {in }}(t)_{+}-\alpha_{1} \sqrt{\beta_{1} \beta_{2}} V_{\text {in }}(t)_{-}\right\}
$$

It can be observed from the above equation that the gain obtained in the positive and negative half-cycle of the applied input Voltage signal is not identical. So, keen attention 
must be paid while implementing DVCCTA to make sure that the output Voltage is given by (10) is met. To compensate for the non-unity gain $\alpha_{i}, \beta_{i}$, and $\gamma_{i}$, a slight adjustment in the biasing Voltage used to bias the NMOS transistor is needed.

\section{Parasitic Analysis of the Proposed Rectifier Circuit}

The behavior of the proposed design of the full-wave rectifier will be influenced due to the presence of parasitic resistance and capacitance. $R_{X 1}, R_{X 2}, R_{Z 1}, R_{Z 2}, R_{Y 11}, R_{Y 12}$, and $R_{O}$ are the parasitic resistances at terminal $X, Z, Y$, and $O$ respectively. $C_{X 1}, C_{X 2}, C_{Z 1}, C_{Z 2}, C_{Y 11}$, $\mathrm{C}_{\mathrm{Y} 12}$, and $\mathrm{C}_{\mathrm{O}}$ are the parasitic capacitances at the terminal of $\mathrm{X}, \mathrm{Z}, \mathrm{Y}$, and $\mathrm{O}$ respectively. The Value of parasitic resistances and capacitances connected in parallel at $Y, Z$, and $O$ terminals are $R_{Y}=$ Very high, $R_{Z}=190 \mathrm{k} \Omega, R_{O}=175 \mathrm{k} \Omega, C_{Y}=40 \mathrm{fF}, C_{Z}=0.9 \mathrm{pF}, \mathrm{C}_{\mathrm{O}}=12 \mathrm{fF}$. The parasitic resistance connected in series at $X$ terminal is $11 \Omega$. The parasitic resistance at the $X$ terminal of DVCCTA has not been considered for the sake of calculation. These resistances will not have much effect at a higher frequency, but make the calculation much more complex.

Considering the parasitic component present at the terminal of DVCCTA as shown in Figure 4, the current $I_{d 2}$ and $I_{d 3}$ for the positive half-cycle of the applied input signal can be written as:

$$
\begin{gathered}
I_{d 2}=\frac{K_{n}}{2}\left[V_{i n}(t)_{+}\right]^{2}+\frac{V_{i n}(t)_{+}}{\left(R_{Z 1} \| C_{Z 1}\right)} \\
I_{d 3}=\frac{K_{n}}{2}\left[V_{Z}(t)\right]^{2}+\frac{V_{Z}(t)}{\left(R_{Z 2} \| C_{Z 2}\right)}
\end{gathered}
$$

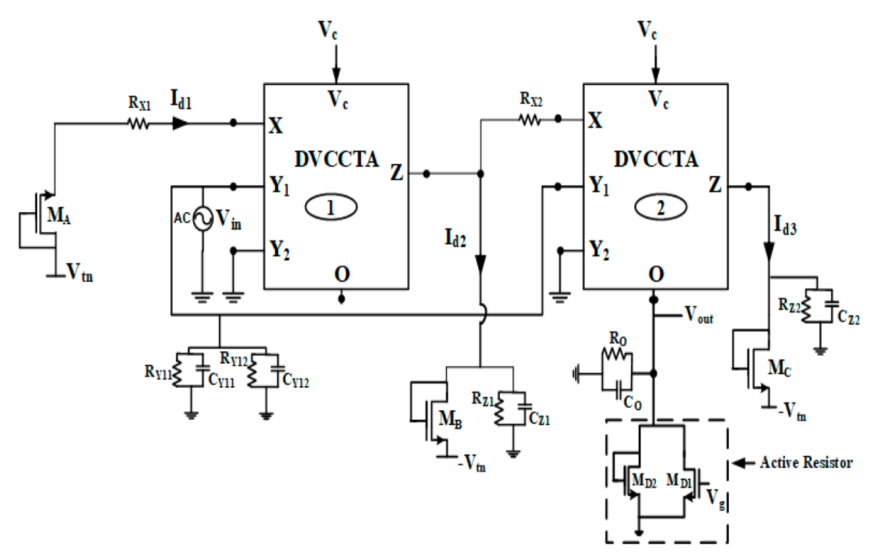

Figure 4. Full-wave rectifier circuit considering parasitic.

Using the port relationships of DVCCTA, the current Equations (18) and (19) are equated and written as:

$$
\frac{K_{n}}{2}\left[V_{Z}(t)\right]^{2}+\frac{V_{Z}(t)}{\left(R_{Z 2} \| C_{Z 2}\right)}=\frac{K_{n}}{2}\left[V_{i n}(t)_{+}\right]^{2}+\frac{V_{i n}(t)_{+}}{\left(R_{Z 1} \| C_{Z 1}\right)}
$$

It can be observed that the obtained Equation (20) is non-linear due to the presence of parasitic components for a positive half-cycle. The Voltage at terminal Z of DVCCTA-2 can be written as:

$$
V_{Z}(t)=V_{\text {in }}(t)_{+} \text {when } \frac{V_{Z}(t)}{\left(R_{Z 2} \| C_{Z 2}\right)}=\frac{V_{\text {in }}(t)_{+}}{\left(R_{Z 1} \| C_{Z 1}\right)}
$$

For the negative half-cycle of the applied input signal, the current $I_{d 1}$ can be written as:

$$
I_{d 1}=\frac{K_{n}}{2}\left[-V_{i n}(t)_{-}\right]^{2}
$$


Using the port relationships of DVCCTA, the current Equations (19) and (22) are equated and written as:

$$
\frac{K_{n}}{2}\left[V_{Z}(t)\right]^{2}+\frac{V_{Z}(t)}{\left(R_{Z 2} \| C_{Z 2}\right)}=\frac{K_{n}}{2}\left[-V_{i n}(t)_{-}\right]^{2}
$$

It can be observed that the obtained Equation (23) is non-linear due to the presence of parasitic components for the negative half-cycle. The Voltage at terminal Z of DVCCTA-2 can be written as:

$$
V_{Z}(t)=-V_{\text {in }}(t)_{-} \text {when } \frac{V_{Z}(t)}{\left(R_{Z 2} \| C_{Z 2}\right)}=0
$$

The output of the rectifier circuit using (21) and (23) can be written as:

$$
V_{O}(t)=g_{m}\left\{R_{D} V_{Z}+V_{Z}\left(R_{O} \| C_{O}\right)\right\}
$$

When

$$
\frac{V_{Z}(t)}{\left(R_{Z 2} \| C_{Z 2}\right)}=\frac{\operatorname{Vin}(t)_{+}}{\left(R_{Z 1} \| C_{Z 1}\right)}
$$

It can be observed from (25) that the output of the proposed full-wave rectifier circuit is affected at a higher frequency due to the presence of parasitic components.

\section{Simulation Results}

This section shows the simulation outcome of the proposed electronically tunable full-wave rectifier circuit simulated using $0.25 \mu \mathrm{m}$ TSMC CMOS technology having a supply Voltage of $\pm 1.5 \mathrm{~V}$. The internal structure of DVCCTA shown in Figure 2 is used for simulation considering the applied bias Voltage $V_{b}=-1 \mathrm{~V}$. The $\mathrm{W} / \mathrm{L}$ or commonly known as the aspect ratio of transistors used for implementing DVCCTA is provided in Table 1. The threshold Voltage of NMOS transistor $\mathrm{M}_{\mathrm{A}}, \mathrm{M}_{\mathrm{B}}$, and $\mathrm{M}_{\mathrm{C}}$ used in Figure 3 are $0.425 \mathrm{~V}, 0.423 \mathrm{~V}$, and $0.44 \mathrm{~V}$ respectively are chosen to compensate for the current gain and Voltage gain due to non-ideality as discussed in Section 4. The transconductance parameter of DVCCTA Varied depending on the range of controlling Voltage $V_{c}$. The Value of $V_{c}$ lies in the range of $-0.5-0.5 \mathrm{~V}$. The output of the rectifier circuit is obtained from terminal O of DVCCTA-2 by controlling $V_{g}$. The Value of the $\mathrm{R}_{\mathrm{D}}$ resistor is around $2.5 \mathrm{k} \Omega$. Figure 5 shows the DC Voltage transfer characteristic of the full-wave rectifier circuit at $V_{c}=0.5 \mathrm{~V}, V_{g}=0.6 \mathrm{~V}$ and it can be observed that the maximum input signal amplitude obtained is approximately $200 \mathrm{mV}$. The transistor at the input stage of the internal structure of DVCCTA shown in Figure 2 is no longer in the saturation region when the input Voltage lies outside this range.

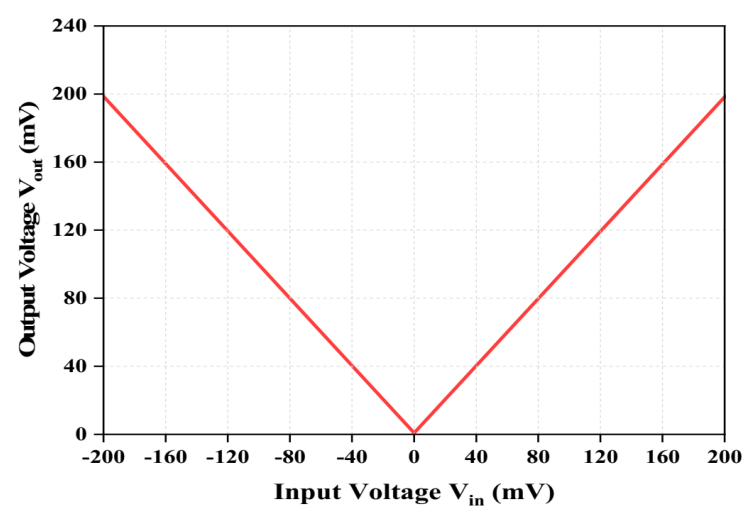

Figure 5. DC Voltage transfer characteristic of the proposed full-wave rectifier circuit.

The transient response of the rectifier circuit is presented in Figures 6-8 considering the magnitude of the applied input signal as $30 \mathrm{mV}, 50 \mathrm{mV}$, and $100 \mathrm{mV}$, respectively, at 
frequency $1 \mathrm{MHz}$. It can be observed from Figure 6 that the rectified output signal is obtained at $\mathrm{V}_{\mathrm{C}}=0.3 \mathrm{~V}$ and $0.35 \mathrm{~V}$ considering the constant Value of $\mathrm{Vg}=0.56 \mathrm{~V}$ when the input signal is of $30 \mathrm{mV}$ amplitude at $1 \mathrm{MHz}$ frequency. It can be observed from Figure 7 that the rectified output signal is obtained at $\mathrm{V}_{\mathrm{C}}=0.38 \mathrm{~V}, 0.40 \mathrm{~V}$, and $0.42 \mathrm{~V}$ considering the constant Value of $\mathrm{Vg}=0.56 \mathrm{~V}$ when the amplitude of the applied input signal is $50 \mathrm{mV}$ at $1 \mathrm{MHz}$ frequency. The rectified output coincides with the input signal at $\mathrm{V}_{\mathrm{C}}=0.40 \mathrm{~V}$. It can be observed from Figure 8 that the rectified output signal is obtained at $\mathrm{V}_{\mathrm{C}}=0.40 \mathrm{~V}, 0.42 \mathrm{~V}$, and $0.44 \mathrm{~V}$ considering the constant Value of $\mathrm{Vg}=0.56 \mathrm{~V}$ taking input signal as $100 \mathrm{mV}$ in amplitude and having $1 \mathrm{MHz}$ frequency. The rectified output coincides with the input signal at $\mathrm{V}_{\mathrm{C}}=0.42 \mathrm{~V}$. It can be observed from Figure 9 that the rectified output signal is obtained at $\mathrm{Vg}=0.54 \mathrm{~V}, 0.56 \mathrm{~V}$, and $0.60 \mathrm{~V}$ considering the constant Value of $\mathrm{V}_{\mathrm{C}}=0.34 \mathrm{~V}$ while using input signal of amplitude $50 \mathrm{mV}$ at $1 \mathrm{MHz}$ frequency. The rectified output coincides with the input signal at $\mathrm{Vg}=0.56 \mathrm{~V}$. Figures 6-9 show that the rectified output of the proposed rectifier circuit can be tuned by changing the Value of $\mathrm{V}_{\mathrm{C}}$ and $\mathrm{Vg}$. The radical temperature change in the time domain and the DC characteristic is shown in Figure 10.

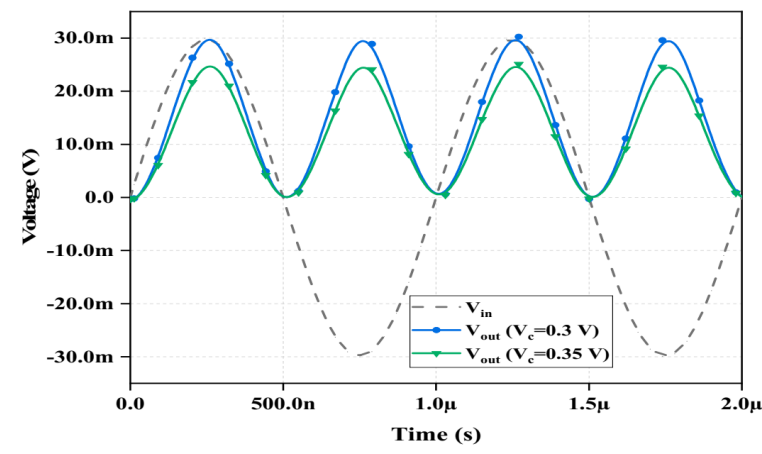

Figure 6. Transient response of full-wave rectifier circuit at frequency $\mathrm{f}=1 \mathrm{MHz}$ and $\mathrm{V}_{\mathrm{P}}=30 \mathrm{mV}$ considering Variable $\mathrm{V}_{\mathrm{C}}$.

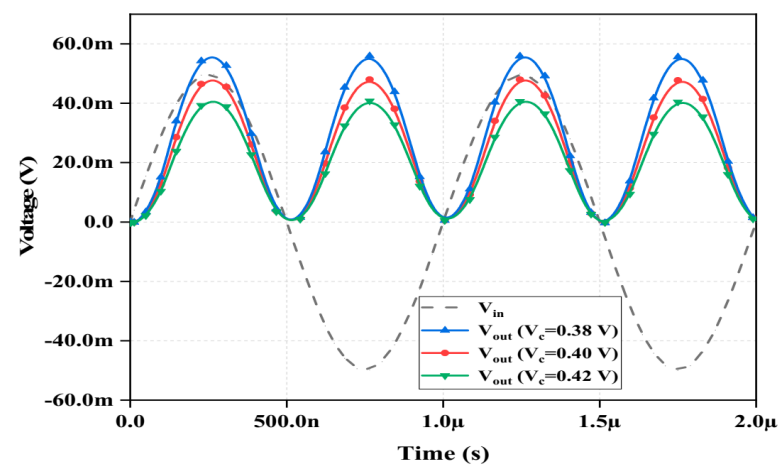

Figure 7. Transient response at frequency $\mathrm{f}=1 \mathrm{MHz}$ and $\mathrm{V}_{\mathrm{P}}=50 \mathrm{mV}$ considering Variable $\mathrm{V}_{\mathrm{C}}$.

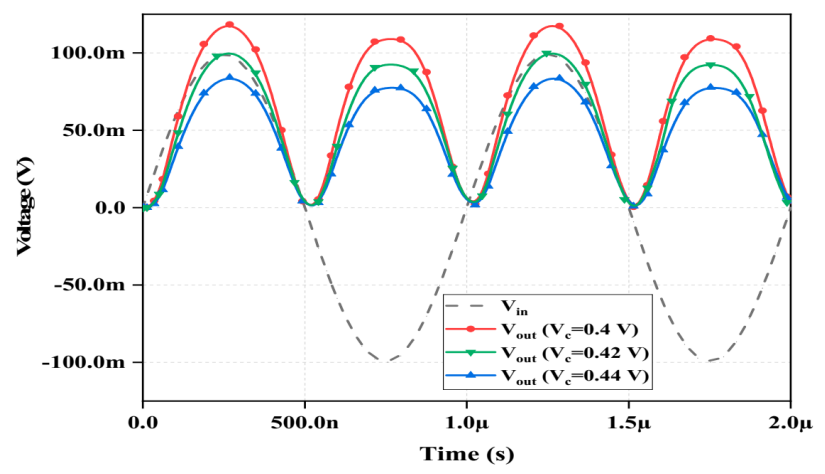

Figure 8. Transient response at frequency $f=1 \mathrm{MHz}$ and $\mathrm{V}_{\mathrm{P}}=100 \mathrm{mV}$ considering Variable $\mathrm{V}_{\mathrm{C}}$. 


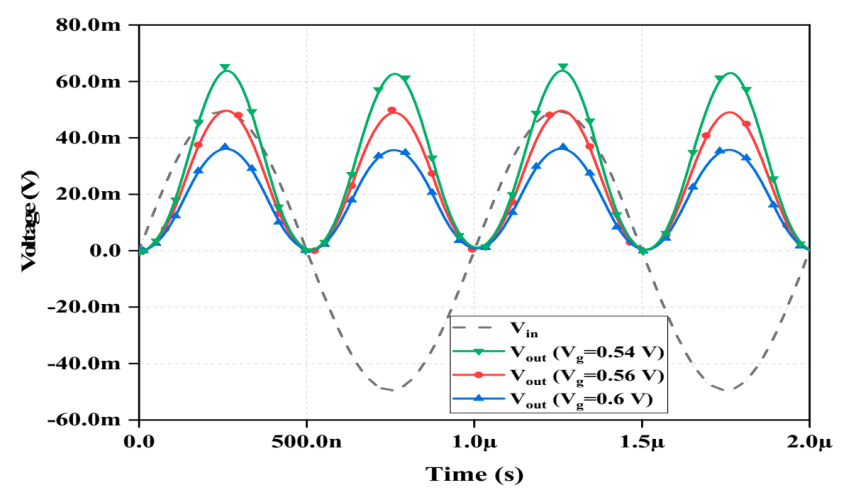

Figure 9. Transient response at frequency $f=1 \mathrm{MHz}$ and $V_{P}=50 \mathrm{mV}$ considering Variable $V_{g}$.
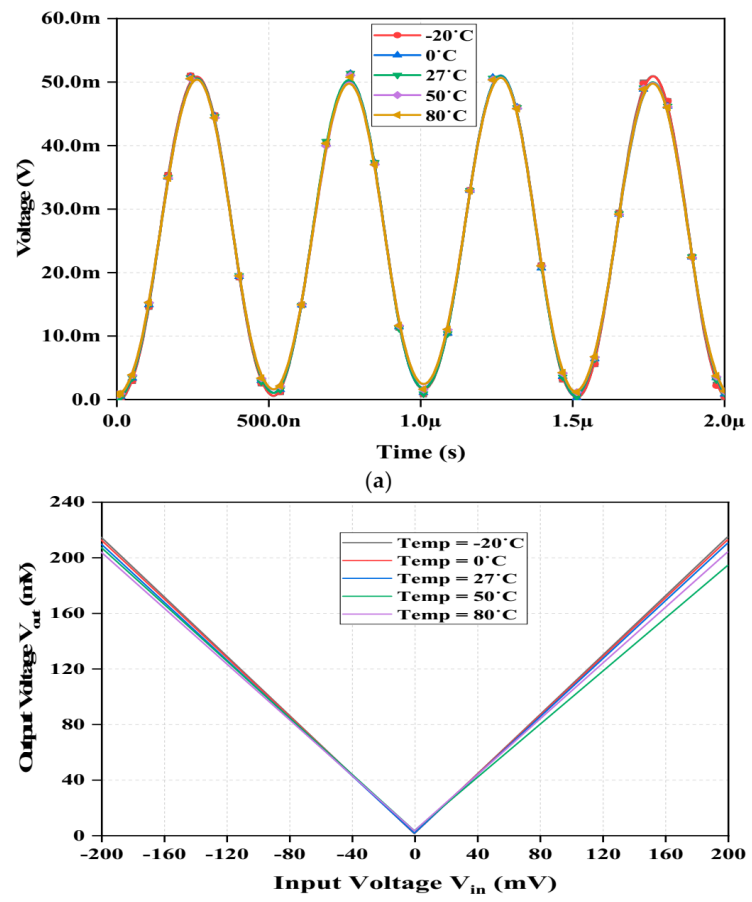

(b)

Figure 10. Temperature analysis of the proposed rectifier circuit (a) Transient response (b) Input and output DC characteristics.

A Variable ambient temperature from -20 to $80^{\circ} \mathrm{C}$ is considered to show the robustness of the presented design. It can be observed that the rectified signal amplitude shows a minute deviation with temperature. The performance study that includes the Monte Carlo Sampling simulation offers a unique tool to study and analyze the robustness as well as the uncertainty of the proposed full-wave rectifier circuit for transistor mismatch in the designed circuit when the input signal of amplitude $50 \mathrm{mV}$ is applied at frequency $1 \mathrm{MHz}$. MCS simulation is done for 200 runs by considering a 3\% mismatch in gate oxide thickness $\left(\mathrm{T}_{\mathrm{ox}}\right)$ of all transistors as shown in Figure 11a. The DC Monte Carlo analysis is shown in Figure $11 \mathrm{~b}$. It is seen that the rectifier circuit is still operational within acceptable limits despite having a slight deviation in the output response. Corner analyses, such as SS, FF, and TT, have been carried out as shown in Figure 12 and even these analyses show that the rectifier circuit presented here is capable of exhibiting superior operational performance. Henceforth, this makes the proposed circuit suitable in operation under radical conditions and over a wide range of temperatures as well. The layout of the proposed full-wave rectifier circuit is created and depicted as shown in Figure 13 and post-layout simulation has been done to present the effect of the involved parasitics on the overall performance of the rectifier circuit. It covers an overall layout area of $9044 \mu \mathrm{m}^{2}(133 \mu \mathrm{m} \times 68 \mu \mathrm{m})$. It 
can be observed from Figure 13c that the transient response of the pre and post-layout simulation differs slightly with respect to one another which clearly shows the effects of parasitic in the design. Due to the presence of significant interconnection resistance, the distributed resistance and parasitic capacitance will influence the overall performance of the rectifier design and even lead to delays between pre- and post-layout results. The important performance parameter of the rectifier circuit is the DC Value transfer $\left(\mathrm{P}_{\mathrm{DC}}\right)$ and RMS error ( $\left.\mathrm{P}_{\mathrm{RMS}}\right)[27,28]$, which are used to show the accuracy of the rectifier. In the ideal case, the Values of $P_{D C}$ and $P_{R M S}$ should be 1 and 0 , respectively. The simulation results of $\mathrm{P}_{\mathrm{DC}}$ and $\mathrm{P}_{\mathrm{RMS}}$ have been shown in Figure 14. It can be seen that the deviations in the actual output Voltage can be observed by increasing the frequency and decreasing the magnitude of the input signal. The $P_{D C}$ decreases below one and $P_{R M S}$ increases when the magnitude of the input signal decreases from $100 \mathrm{mV}$ to $10 \mathrm{mV}$. The simulation results obtained at frequency $1 \mathrm{MHz}$ and $V_{\text {in }}=100 \mathrm{mV}$ have been compared with the results provided in $[8,29,31]$ as shown in Figure 15 and it can be observed that [8] responds slowly and has a dead zone due to the presence of diode. Initially, [29] shows phase difference compared to the input signal, and [31] shows Variations in the magnitude of the output response.

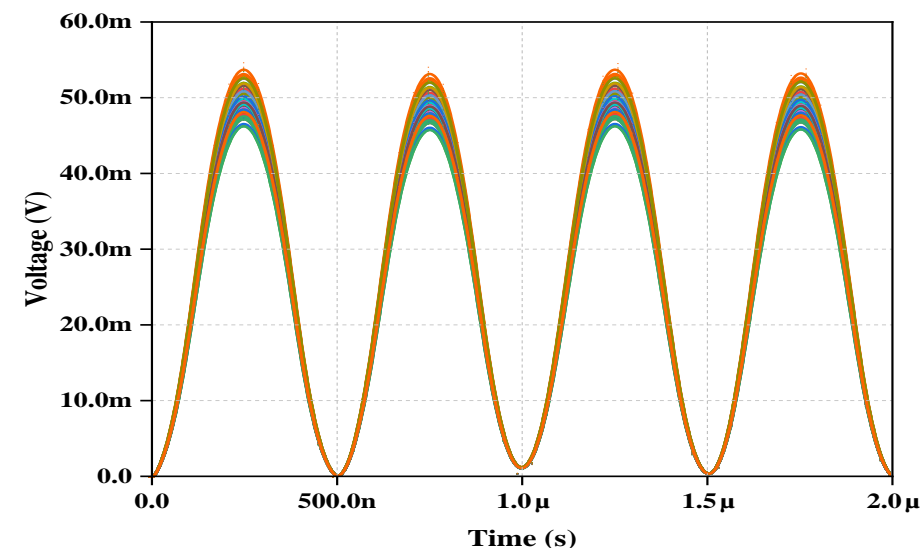

(a)

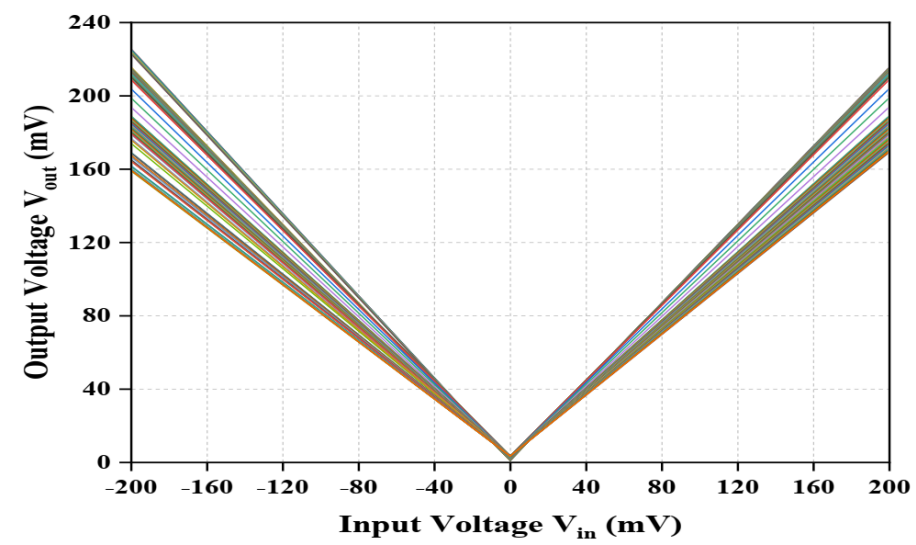

(b)

Figure 11. Monte Carlo sampling response of the presented rectifier circuit (a) Time response (b) Input-output DC characteristics. 


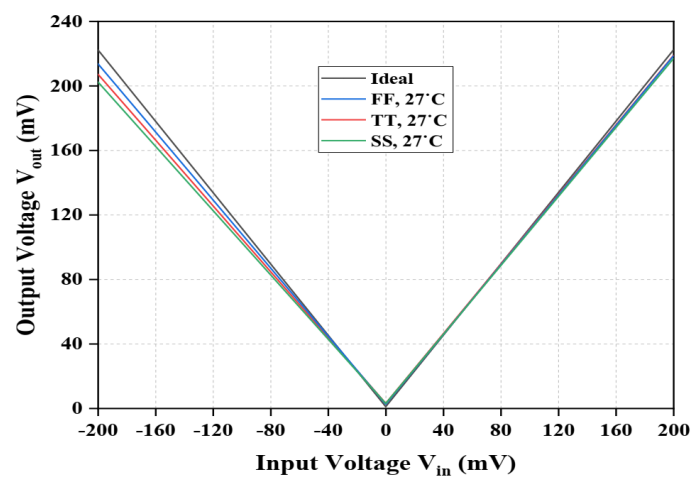

Figure 12. Process corner analysis of the proposed full-wave rectifier circuit.

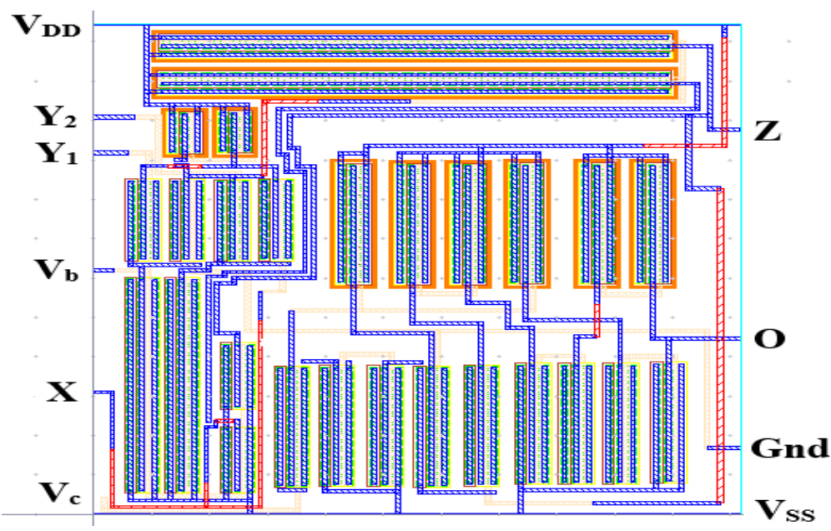

(a)

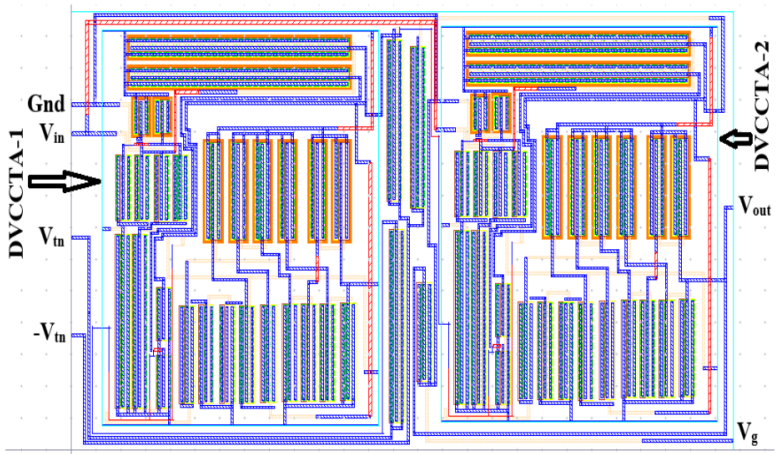

(b)

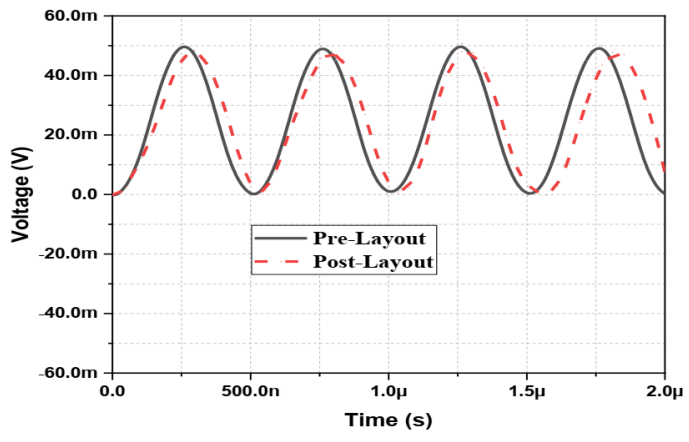

(c)

Figure 13. Layout of the proposed rectifier circuit (a) Layout of DVCCTA (b) Layout of the full-wave rectifier (c) Transient response of pre and post-layout simulation. 


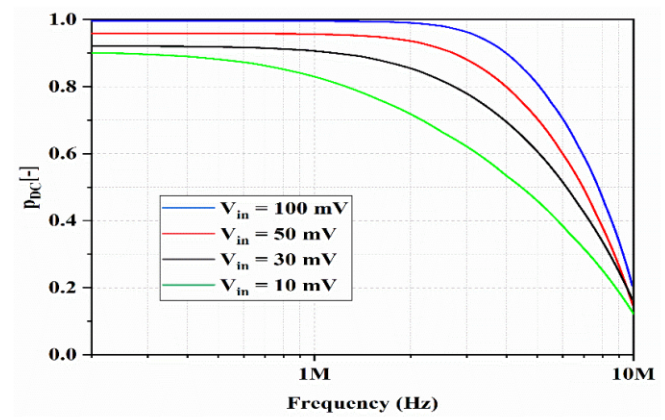

(a)

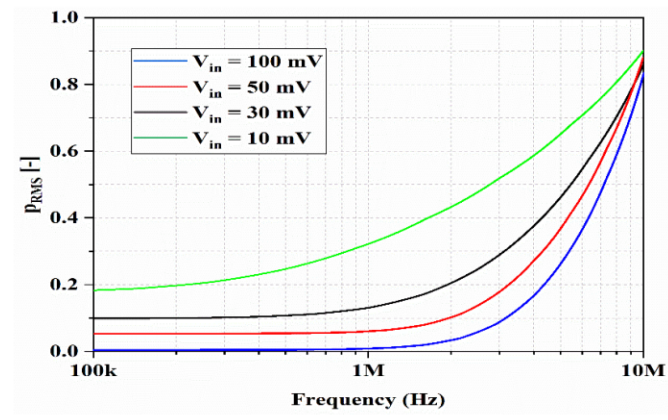

(b)

Figure 14. (a) Transfer Value $P_{D C}$ for different input signal magnitude (b) RMS error $P_{R M S}$ for different input signal magnitude.

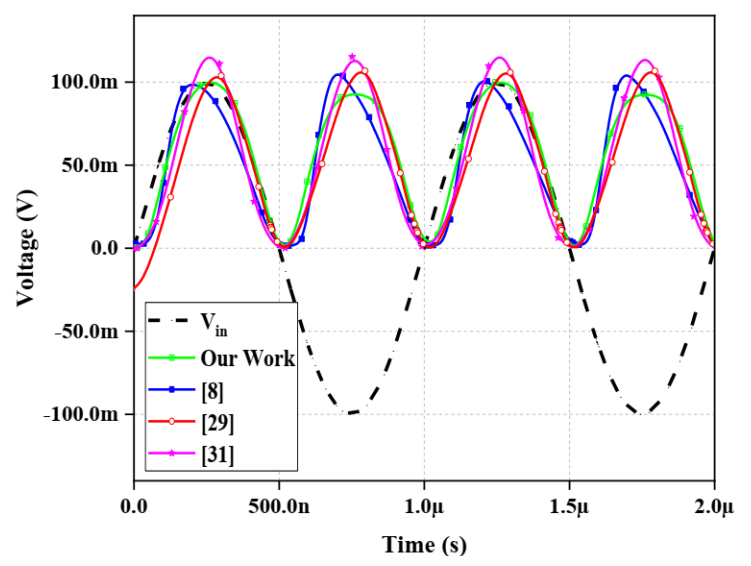

Figure 15. Comparison of simulation results obtained for $[8,29,31]$ with presented rectifier design at frequency $1 \mathrm{MHz}$ and $\mathrm{V}_{\text {in }}=100 \mathrm{mV}$.

\section{Experimental Results}

Since the monolithic IC of DVCCTA is not commercially available, the presented electronically tunable full-wave rectifier circuit based on the current-mode scheme was implemented on the breadboard, using commercially available CA3080 and AD844AN circuits to experimentally justify the operation of the circuit. The MOS-based rectifier design as shown in Figure 3 is implemented using the macro model circuit consisting of commercial ICs for performing the experiment as shown in Figure 16. DVCCTA implementation requires one CA3080 and three AD844AN ICs along with four passive resistors (R), each resistance having a Value of $1 \mathrm{k} \Omega$. Since two DVCCTA blocks are used along with NMOS transistors, a total of six AD844AN and two CA3080 ICs with three NMOS transistors (IRF540N) is required for implementing the experimental prototype. Figure 16a shows the implementation of DVCCTA using commercial ICs. Figure 16b shows the micromodel circuit implementation of the proposed rectifier design using commercial ICs and its implementation on the breadboard is shown in Figure 16c. A sinusoidal input having an amplitude of $50 \mathrm{mV}$ is fed as an input to the circuit and component parameter $R_{\mathrm{D}}$ of $2.2 \mathrm{k} \Omega$ 
is considered to obtain the output waveform curve as shown in Figure 17. Commonly available Keysight-DSOX3054A digital storage oscilloscope is used for this purpose. The amplitude of the output waveform depends on the bias current and increment in the amplitude is observed with the increment in bias current. The experiment is performed at a frequency of $500 \mathrm{kHz}$. Commercially available IC CA3080 is current biased $\left(\mathrm{I}_{\mathrm{B}}\right)$ as shown in the DVCCTA implementation in Figure 17 and it is exploited for Varying the amplitude of the output waveform. It is clearly apparent that the amplitude of the output waveform in the presented precision rectifier Varies in accordance with the bias current of the OTA used in the implementation of DVCCTA.

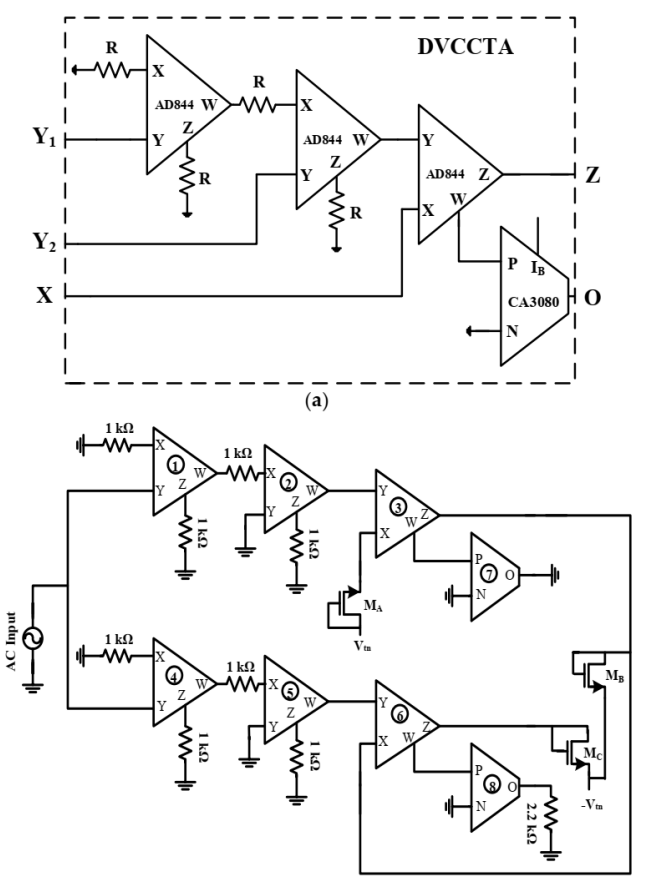

(b)

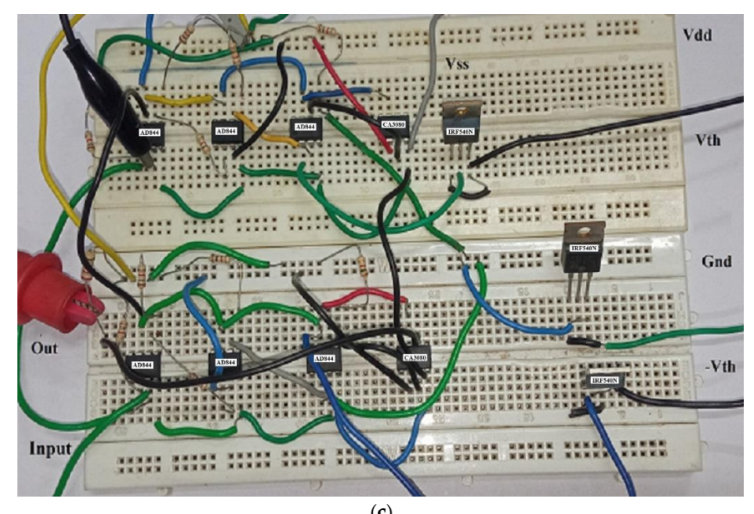

Figure 16. Macro model circuit (a) DVCCTA (b) Rectifier circuit (c) Breadboard implementation using commercial ICs.

It can be observed that the output waveform shows a minute offset owing to the presence of tracking errors, parasitic involved, and mismatch in the transistors. The prototype circuit realized and implemented on a breadboard offers some frequency limitations and it can be noted that the bandwidth in the experimental setup is approximately $2 \mathrm{MHz}$ since these commercial ICs are prone to frequency limitations and parasitic effects arising because of the interconnection between the components. 

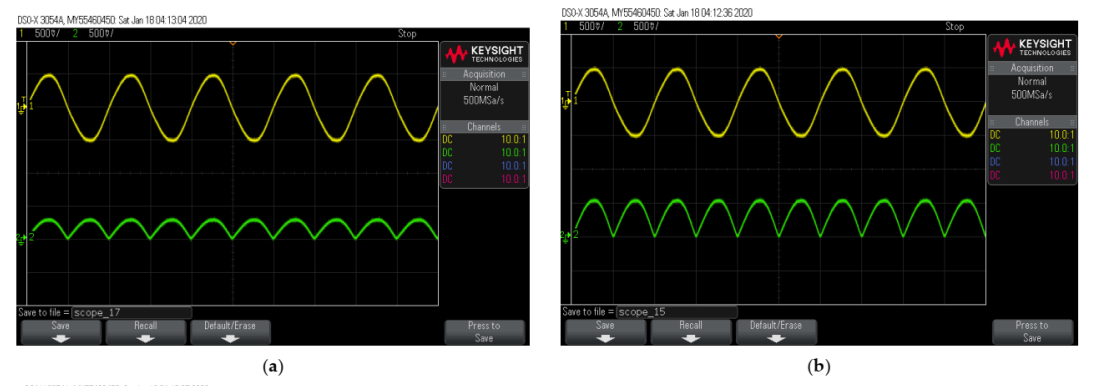

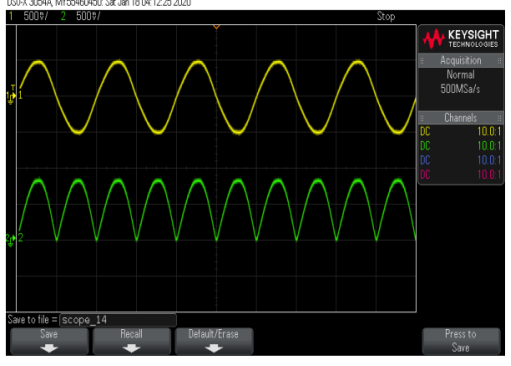

(c)

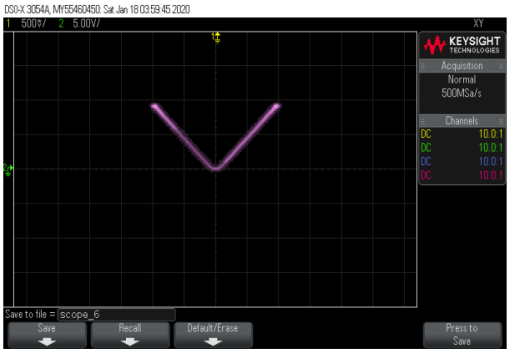

(d)

Figure 17. Experimental result obtained using commercial ICs (a) At bias current $50 \mu \mathrm{A}$ (b) At bias current $100 \mu \mathrm{A}$ (c) At bias current $200 \mu \mathrm{A}$ (d) DC transfer characteristic.

\section{Comparison}

The performance of the presented full-wave rectifier circuit is compared with the available existing literature as shown in Table 2 in terms of tunability, the number of passive components, input, and output impedance. As evident from Table 2, the presented design of the full-wave rectifier circuit contains high input impedance along with low output impedance as well. Moreover, it does not require any passive components and provides electronic tunability features. The recent articles in literature [19-22,25-36] present rectifier design, but most of them do not provide tunability features (see Table 2).

Table 2. Comparison of proposed rectifier circuit with existing literature.

\begin{tabular}{|c|c|c|c|c|c|c|}
\hline Ref. No & $\begin{array}{l}\text { Number of Active } \\
\text { Components }\end{array}$ & Tunability & $\begin{array}{c}\text { Number of } \\
\text { Floating Resistors }\end{array}$ & $\begin{array}{c}\text { Number of } \\
\text { Grounded Resistors }\end{array}$ & $\begin{array}{l}\text { High Input } \\
\text { Impedance }\end{array}$ & $\begin{array}{l}\text { Low Output } \\
\text { Impedance }\end{array}$ \\
\hline [2] & $\begin{array}{c}1 \mathrm{CCII}+ \\
1 \mathrm{CM}\end{array}$ & No & 2 & 2 & Yes & No \\
\hline [3] & 2 CCIIs & No & 2 & 1 & Yes & No \\
\hline [4] & 3 CCCIIs & No & 5 & 2 & Yes & No \\
\hline [5] & 1 DO-OTA & No & 1 & 1 & Yes & No \\
\hline [6] & $\begin{array}{l}2 \text { CCIIs } \\
3 \text { NMOS }\end{array}$ & No & 0 & 0 & No & No \\
\hline [7] & $\begin{array}{l}1 \text { DXCCII } \\
3 \text { NMOS }\end{array}$ & No & 0 & 0 & Yes & No \\
\hline [8] & $\begin{array}{c}1 \mathrm{CCII} \\
1 \text { Op-Amp }\end{array}$ & No & 3 & 2 & Yes & Yes \\
\hline [9] & $\begin{array}{l}1 \mathrm{CCII} \\
1 \mathrm{UVC}\end{array}$ & No & 2 & 2 & Yes & Yes \\
\hline [10] & $\begin{array}{l}1 \mathrm{CCII} \\
1 \mathrm{UVC}\end{array}$ & No & 3 & 3 & Yes & No \\
\hline [11] & 2 CCIIs & No & 3 & 1 & Yes & No \\
\hline [12] & 2 CCIIs & No & 2 & 1 & Yes & No \\
\hline
\end{tabular}


Table 2. Cont.

\begin{tabular}{|c|c|c|c|c|c|c|}
\hline Ref. No & $\begin{array}{l}\text { Number of Active } \\
\text { Components }\end{array}$ & Tunability & $\begin{array}{c}\text { Number of } \\
\text { Floating Resistors }\end{array}$ & $\begin{array}{c}\text { Number of } \\
\text { Grounded Resistors }\end{array}$ & $\begin{array}{l}\text { High Input } \\
\text { Impedance }\end{array}$ & $\begin{array}{l}\text { Low Output } \\
\text { Impedance }\end{array}$ \\
\hline [13] & $\begin{array}{c}2 \text { DVCCs } \\
1 \text { NMOS } \\
1 \mathrm{VF}\end{array}$ & No & 3 & 0 & No & Yes \\
\hline$[14]$ & 1 CCII- & No & 2 & 1 & No & No \\
\hline [15] & $\begin{array}{c}1 \mathrm{CCII} \\
28 \mathrm{MOS}\end{array}$ & No & 1 & 1 & Yes & Yes \\
\hline [16] & 2 DVCC + & No & 2 & 2 & Yes & Yes \\
\hline [17] & 2 CFOAs & No & 0 & 0 & Yes & Yes \\
\hline [18] & $\begin{array}{c}1 \mathrm{MO}-\mathrm{CCII} \\
1 \mathrm{ZCD} \\
2 \mathrm{MOS}\end{array}$ & Yes & 0 & 1 & No & Yes \\
\hline [19] & $\begin{array}{c}2 \mathrm{VC} \\
2 \text { Diode }\end{array}$ & No & 0 & 1 & Yes & Yes \\
\hline [20] & $\begin{array}{l}1 \mathrm{DO}-\mathrm{CCII} \\
12 \mathrm{MOS}\end{array}$ & No & 0 & 0 & No & No \\
\hline [21] & $\begin{array}{l}1 \mathrm{OC} \\
4 \mathrm{CM}\end{array}$ & No & 0 & 2 & NA & NA \\
\hline [22] & $\begin{array}{l}1 \mathrm{DX}-\mathrm{CCII} \\
2 \mathrm{MOS}\end{array}$ & No & 1 & 1 & Yes & No \\
\hline [25] & $\begin{array}{l}1 \text { EXCCII } \\
2 \mathrm{MOS}\end{array}$ & No & 0 & 0 & No & No \\
\hline [26] & $\begin{array}{l}1 \mathrm{DDCC} \\
2 \mathrm{MOS}\end{array}$ & No & 0 & 3 & Yes & No \\
\hline [27] & 2 WAT & No & 0 & 0 & No & No \\
\hline [28] & $\begin{array}{c}1 \mathrm{CCII} \\
1 \text { DX-CCII } \\
2 \text { Diode }\end{array}$ & No & 1 & 1 & No & No \\
\hline [29] & $\begin{array}{l}1 \text { OTA } \\
2 \text { Diode }\end{array}$ & Yes & 0 & 2 & Yes & No \\
\hline [30] & $\begin{array}{l}1 \mathrm{CCCII} \\
4 \mathrm{MOS}\end{array}$ & No & 0 & 1 & Yes & No \\
\hline [32] & $\begin{array}{l}1 \text { COMP } \\
2 \text { CM } \\
2 \text { Diode }\end{array}$ & No & 0 & 0 & No & No \\
\hline [33] & $\begin{array}{l}1 \text { OTA } \\
2 \text { MOS }\end{array}$ & Yes & 0 & 2 & Yes & No \\
\hline [34] & $\begin{array}{l}3 \text { OTRA } \\
6 \mathrm{MOS}\end{array}$ & Yes & 8 & 0 & No & No \\
\hline [35] & $\begin{array}{l}1 \text { CDTA } \\
4 \text { Diode }\end{array}$ & Yes & 0 & 1 & No & Yes \\
\hline [36] & $2 \mathrm{CM}$ & No & 1 & 0 & No & No \\
\hline Our work & $\begin{array}{l}2 \text { DVCCTA } \\
5 \text { NMOS }\end{array}$ & Yes & 0 & 0 & Yes & Yes \\
\hline
\end{tabular}

\section{Conclusions}

A precision full-wave rectifier circuit using DVCCTA with five NMOS transistors is presented in this article. The proposed design of the full-wave rectifier circuit offers some useful features, such as tunability, high input impedance, low output impedance, and better 
slew rate. Due to the aforementioned features, the circuit designed can be easily cascaded with other Voltage-mode counterparts. The simulation results provide confirmation about the effectiveness of the proposed circuit in operation over a wide range of frequencies. The presented design has a chip area of $9044 \mu^{2}$. Moreover, the simulation results and experimental implementation carried out are in agreement with the theoretical model. The impact of non-ideality and tracking errors was assessed to analyze the performance of the proposed rectifier circuit. Moreover, the corner analysis and Monte Carlo sampling were performed to examine the robustness of the presented rectifier circuit design.

Author Contributions: Research methodology, N.R., S., R.K.R., B.P., and N.B.; writing-original draft preparation, N.R., S., and R.K.R.; supervision, R.K.R.; Validation, R.K.R. and N.B.; writingreview and editing, N.B. and R.K.R. All authors have read and agreed to the published Version of the manuscript.

Funding: This research received no external funding.

Conflicts of Interest: The authors declare no conflict of interest.

\section{References}

1. Tietze, U.; Schenk, C.; Gramm, E. Electronic Circuits-Handbook for Design and Application; Springer: Berlin/Heidelberg, Germany, 2015.

2. Monpapassorn, A.; Dejhan, K.; Cheevasuvit, F. A full-wave rectifier using a current conveyor and current mirrors. Int. J. Electron. 2001, 88, 751-758. [CrossRef]

3. Toumazou, C.; Lidgey, F.J.; Chattong, S. High frequency current conveyor precision full-wave rectifier. Electron. Lett. 1994, 30, 745-746. [CrossRef]

4. Anuntahirunrat, K.; Tangsrirat, W.; Riewruja, V.; Surakampontorn, W. Sinusoidal frequency doubler and full-wave rectifier using translinear current controlled conveyors. In Proceedings of the 2000 TENCON Proceedings. Intelligent Systems and Technologies for the New Millennium (Cat. No.00CH37119), Kuala Lumpur, Malaysia, 24-27 September 2000; pp. 166-169.

5. Kumngern, M. High frequency and high precision CMOS full-wave rectifier. In Proceedings of the 2010 IEEE International Conference on Communication Systems, Singapore, 17-19 November 2010; pp. 5-8.

6. Yuce, E.; Minaei, S.; Cicekoglu, O. Full-wave rectifier realization using only two CCII+s and NMOS transistors. Int. J. Electron 2006, 93, 533-541. [CrossRef]

7. Minaei, S.; Yuce, E. A new full-wave rectifier circuit employing single Dual-X current conveyor. Int. J. Electron. 2008, 95, 777-784. [CrossRef]

8. Gift, S.G.; Maundy, B. Versatile precision full-wave rectifiers for instrumentation and measurements. IEEE Trans. Instrum. Meas. 2007, 56, 1703-1710. [CrossRef]

9. Koton, J.; Herencsar, N.; Vrba, K. Minimal configuration precision full-wave rectifier using current and Voltage conveyors. IEICE Electron. Express 2010, 7, 844-849. [CrossRef]

10. Koton, J.; Herencsar, N.; Vrba, K. Current and Voltage conveyors in current and Voltage-mode precision full-wave rectifiers. Radio Eng. 2011, 20, 19-24.

11. Monpapassorn, A. Low output impedance dual CCII full-wave rectifier. Int. J. Electron. 2013, 100, 648-654. [CrossRef]

12. Stiurca, D. Truly temperature independent current conveyor precision rectifier. Electron. Lett. 1995, 31, 1302-1303. [CrossRef]

13. Beg, P.I.; Khan, A.; Maheshwari, S. Biphase amplifier based rectifiers using current conveyors. Int. J. Comput. Appl. 2012, 42, 14-18.

14. Yildiz, M.; Minaei, S.; Yuce, E. A high performance full-wave rectifier using a single CCII-, two diodes and two resistors. Sci. Iran. 2017, 24. [CrossRef]

15. Kumngern, M. New Versatile precision rectifier. IET Circuits Devices Syst. 2014, 8, 141-151. [CrossRef]

16. Ibrahim, M.A.; Yuce, E.; Minaei, S. A new DVCC based fully cascadable Voltage-mode full-wave-rectifier. J. Comput. Electron. 2016, 15, 1440-1449. [CrossRef]

17. Yuce, E.; Minaei, S.; Ibrahim, M.A. A novel full-wave rectifier/sinusoidal frequency doubler topology based on CFOAs. Analog. Integr. Circ. Sig. Process 2017, 93, 351-362. [CrossRef]

18. Petrović, P.B. Voltage Mode Electronically Tunable Full-wave Rectifier. J. Microelectron. Electron. Compon. Mater. 2016, 46, $229-237$. [CrossRef]

19. Safari, L. A new Versatile full wave rectifier using Voltage conveyors. AEU Int. J. Electron. Commun. 2020, 122, 153267. [CrossRef]

20. Safari, L.; Yuce, E.; Minaei, S. A new low-power current-mode MOS only Versatile precision rectifier. AEU Int. J. Electron. Commun. 2018, 83, 40-51. [CrossRef]

21. Vesković, M.; Vulović, A.; Vujičić, D.; Popović, B.; Milutinov, M. Precision Full-Wave Rectifier-Practical Realization in Discrete Technology. In Proceedings of the 2020 19th International Symposium INFOTEH-JAHORINA (INFOTEH), East Sarajevo, Bosnia and Herzegovina, 18-20 March 2020; pp. 1-5. 
22. Kumar, A.; Chaturvedi, B. Realization of ASK/BPSK modulators and precision full-wave rectifier using DXCCII. AEU Int. J. Electron. Commun. 2019, 99, 146-152. [CrossRef]

23. Ranjan, R.K.; Raj, N.; Bhuwal, N.; Khateb, F. Single DVCCTA based high frequency incremental/decremental memristor emulator and its application. AEU Int. J. Electron. Commun. 2017, 82, 177-190. [CrossRef]

24. Kushwaha, A.; Paul, S.K. Inductorless realization of Chua's oscillator using DVCCTA. Analog. Integr. Circuits Signal Process. 2016, 88, 137-150. [CrossRef]

25. Das, R.; Paul, S.K. Resistorless current mode precision rectifier using EXCCII. Analog. Integr. Circuits Signal Process. 2020, 103, 511-522. [CrossRef]

26. Kumari, S.; Nand, D. Current-mode Positive and Negative Rectifier based on DDCC suitable for Higher Frequency operations. IOP Conf. Ser. Mater. Sci. Eng. 2021, 1084, 012079. [CrossRef]

27. Koton, J.; Lahiri, A.; Herencsar, N.; Vrba, K. Current-mode dual-phase precision full-wave rectifier using current-mode two-cell winner-takes-all (WTA) circuit. Radioengineering 2011, 20, 428-432.

28. Koton, J.; Vrba, K.; Herencsar, N. Fast Voltage-mode full-wave rectifier using CCII and DXCCII. In Proceedings of the 2013 8th International Conference on Electrical and Electronics Engineering (ELECO), Bursa, Turkey, 28-30 November 2013. [CrossRef]

29. Mehmet, S.; Minaei, S.; Ayten, U.E. Component reduced current-mode full-wave rectifier circuits using single active component. IET CircuitsDevices Syst. 2016, 10, 1-11.

30. Petrović, P.B. Current/voltage mode full-wave rectifier based on a single CCCII. Int. J. Circuit Theory Appl. 2020, 48, 1140-1153. [CrossRef]

31. Sahu, P.P.; Singh, M.; Baishya, A. A novel Versatile precision full-wave rectifier. IEEE Trans. Instrum. Meas. 2010, 59, 2742-2746. [CrossRef]

32. Athipong, V.; Knobnob, B.; Kumngern, M. CMOS precision full-wave and half-wave rectifier. In Proceedings of the 2011 IEEE International Conference on Computer Science and Automation Engineering, Shanghai, China, 10-12 June 2011.

33. Minhaj, N. Electronically controlled precision full-wave rectifier circuits. In Proceedings of the 2009 International Conference on Advances in Recent Technologies in Communication and Computing, Kottayam, India, 27-28 October 2009; pp. $240-243$.

34. Oruganti, S.; Gilhotra, Y.; Pandey, N.; Pandey, R. New topologies for OTRA based programmable precision half-wave and full-wave rectifiers. In Proceedings of the 2017 Recent Developments in Control, Automation \& Power Engineering (RDCAPE), Noida, India, 26-27 October 2017; pp. 327-331.

35. Koton, J.; Herencsar, N.; Vrba, K.; Minaei, S. Precision full-wave current-mode rectifier using current differencing transconductance amplifier. In Proceedings of the 2011 IEEE 3rd International Conference on Communication Software and Networks, Xi'an, China, 27-29 May 2011; pp. 460-463.

36. Khucharoensin, S.; Varakorn, K. High performance CMOS current-mode precision full-wave rectifier (PFWR). In Proceedings of the 2003 International Symposium on Circuits and Systems, Bangkok, Thailand, 25-28 May 2003. 